\title{
EDITORIAL
}

\section{Asian Monsoon Climate Change - Understanding and Prediction}

\author{
Kyung-Ja Ha ${ }^{1}$, June-Yi Lee ${ }^{1}$, Bin Wang ${ }^{2}$, Shang-Ping Xie ${ }^{3}$, and Akio Kitoh ${ }^{4}$ \\ ${ }^{1}$ Pusan National Unversity, Busan, Korea \\ ${ }^{2}$ University of Hawaii, Honolulu, HI, USA \\ ${ }^{3}$ Scripps Institute of Oceanography, La Jolla, CA, USA \\ ${ }^{4}$ University of Tsukuba, Tsukuba, Japan
}

(C) The Korean Meteorological Society and Springer 2017

The Asian monsoon is of enormous importance to landward moisture transportation in the global hydrological cycle. Precipitation is a key element in global water and energy cycle and a major driver of atmospheric general circulation. Impacts of monsoon climate change on water and energy are expected to be severe in Asia. There is no doubt that changes in monsoon precipitation will impose considerable impacts on society and economy (Qiu, 2013). Therefore, a number of research groups have attempted to seek a more fundamental understanding of climate change in the Asian monsoon regions through observational studies and modelling work (Wang,
2006; Chang et al., 2017). The objective and aim of this issue are to understand how monsoon has changed and will change in the course of global climate change contributed by natural variability, natural forcing and anthropogenic forcing (Kim and $\mathrm{Ha}, 2015)$. Figure 1 shows one of the examples for recent changes in the Asian monsoon system addressed in Lee et al. (2017) of this special issue. There was a significant interdecadal shift in mean and extreme of summer monsoon rainfall over Asia occurred around the mid-1990s suggesting that the change in regional sub-monsoon system should be understood in the context of the Asian monsoon change.
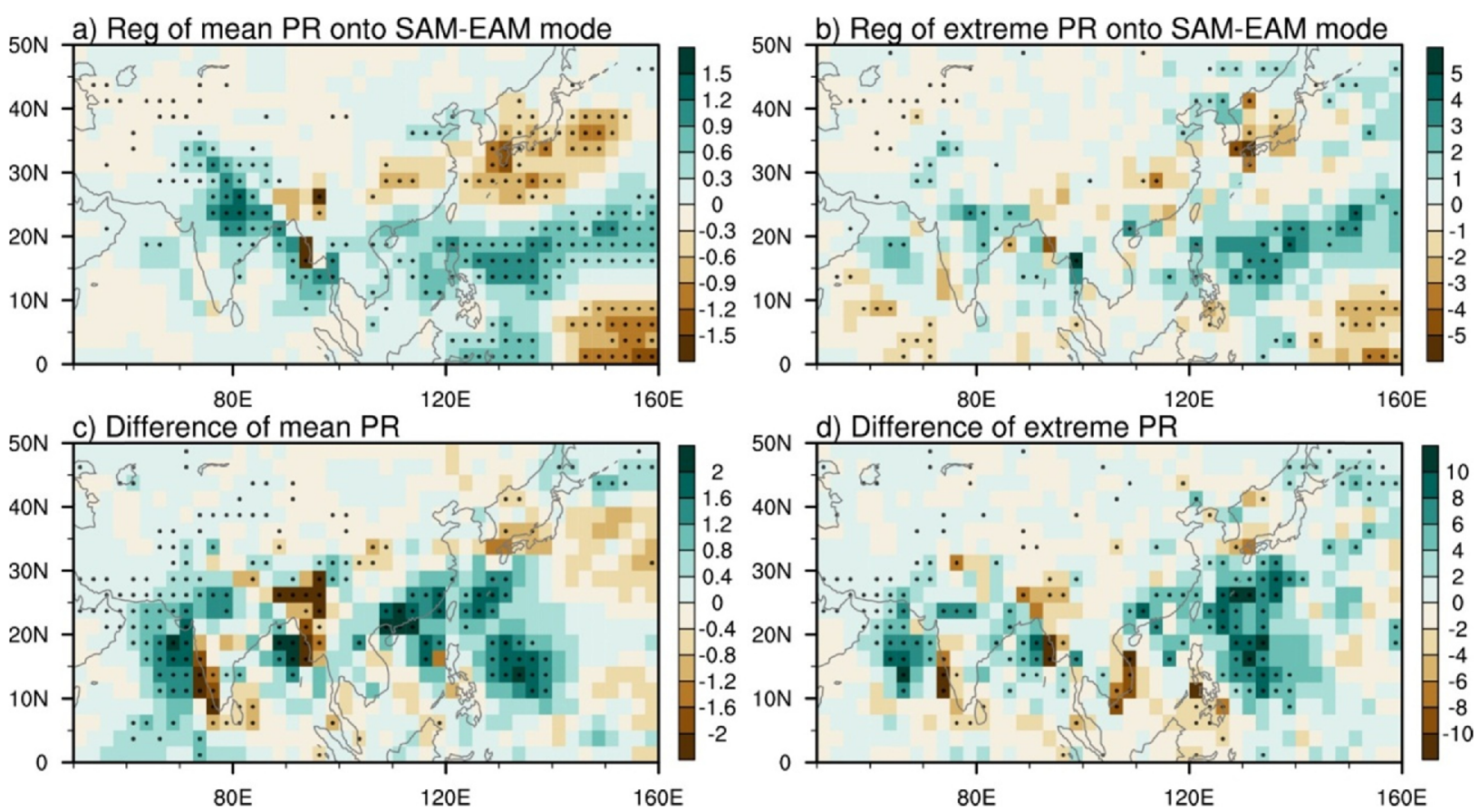

Fig. 1. (a-b) Regression of June-July (a) mean and (b) extreme precipitations against the difference between South Asian monsoon (SAM) and East Asian monsoon (EAM). (c-d) Difference in June-July (c) mean and (d) extreme precipitations between 1994-2013 and 1979-1993. Extreme precipitation is calculated by the maximum of pentad precipitations during June-July. The dots indicate the significant value at the $90 \%$ confidence level. For detail information, refer Lee et al. in this issue. 
Understanding of feedback processes on monsoon variability is the key to identifying predictive sources of climate change. The monsoon climate system involves complex natural atmosphere-ocean-land-ice interaction and is the most difficult to be predicted among various components of the Earth climate system. One of the big challenges facing the Asian monsoon research community is how to obtain more reliable predictions of future monsoon change given the fact the current models have deficiencies in reproducing and predicting the mean and variability of the Asian and sub-regional monsoon system (Chang et al., 2017).

The science pertaining to the Asian monsoon has advanced tremendously in the last three decades with increased data from satellite observation and high-resolution reanalysis data. This special issue intends to advance our understanding on monsoon dynamics and variability in the context of climate change and provide reliable prediction for Asian monsoon changes on various time scales. In view of the topics of monsoon variability and underlying dynamics, leading scientists of the monsoon research fields worldwide were invited to contribute to this special issue with original and review articles. Particular attention is given to the recent progress made in the monsoon variability and extremes, their changes and predictability under global warming over the Asian monsoon region, including detection and attribution, prediction and projection. The papers in this special issue are categorized into three themes, which are (1) monsoon variabilities and their causes, and predictability sources, (2) inter-relationship of regional monsoons, impacts of local and regional climate, and (3) large-scale controls of the Asian monsoon and regional forcing \& feedback responses to changes from observations and models.

Acknowledgements. The guest editors of this issue are grateful to all authors, reviewers, and editorial office of Korean Meteorological Society (KMS) and Asia-Pacific Journal of Atmospheric Sciences (APJAS).

\section{References}

Chang, C.-P., B. Wang, and N. C. G. Lau, 2017: The Global Monsoon System. Research and Forecast. 3rd edition, World scientific, 385 pp.

Kim, B.-H., and K.-J. Ha, 2015: Observed changes of global and western Pacific precipitation associated with global warming SST mode and Mega-ENSO SST mode. Climate Dyn., 45, 3067-3075, doi:10.1007/ s00382-015-2524-2.

Lee, J.-Y., and Coauthors, 2017: The long-term variability of Changma in the East Asian summer monsoon system: A review and revisit. AsiaPac. J. Atmos. Sci., 53, same as this volume.

Qiu, J., 2013: Monsoon melee. Science, 340, 1400-1401, doi:10.1126/ science.340.6139.1400.

Wang, B., 2006: The Asian Monsoon. Springer, 679 pp. 